\title{
O Estatuto Linguístico da Língua Brasileira de Sinais e a Superação do Estigma na Educaçáo de Surdos ${ }^{1,2}$ \\ The Linguistic Statute of Brazilian Sign Language and the Stigma OVERCOMING IN THE EDUCATION OF THE DEAF
}

\author{
Luiz Antonio Gomes SENNA ${ }^{3}$
}

\begin{abstract}
RESUMO: Este estudo tem por objetivo analisar o estatuto linguístico da Língua Brasileira de Sinais (LIBRAS) e as restriçôes que lhe têm sido impostas em virtude da sobreposição de valores oriundos de representaçóes sociais e acadêmicas referentes à palavra. Defende-se aqui que apenas parcialmente se obteve êxito na determinação do estatuto linguístico da LIBRAS, pois, em que pese seu reconhecimento como língua natural, ainda persiste uma leitura de sua estrutura e de seu funcionamento baseada em pressupostos pertencentes ao domínio da palavra. Em consequência disso, tende-se a reforçar o estigma social do sujeito surdo, particularmente no contexto da educação escolar, por meio do que se caracterizará como espetáculo da superaçáo. Trata-se de uma abordagem teórica que busca refletir sobre a real situação da LIBRAS no desenvolvimento da educação escolar do indivíduo surdo, a partir de quatro pontos de vista que se intercomplementam, nos campos da filosofia, da linguística e da psicologia social. Com essa análise, a título de conclusão, focaliza-se a questão da educação escolar do surdo e o papel que nela pode exercer o desenvolvimento de um estatuto linguístico pleno para a LIBRAS.
\end{abstract}

PALAVRAS-CHAVE: LIBRAS - Língua Brasileira de Sinas. Estigma. Educação de surdos

\begin{abstract}
This paper analyzes the linguistic statute given to Brazilian Sign Language and the constraints
imposed on it due to the overlapping of values derived from social and academic representations referring to the word. The assumption here is that it was just partially successful the determination of the Brazilian Sign Language linguistic statute, once, even already recognized as a natural linguistic system, there is still a reading of its structure and its operation based on assumptions pertaining to the word domain. In consequence of this, the tendency to the reinforcement of social stigma associated to the deaf persists, especially in the context of school education, through what will be defined as a spectacle of overcoming. It is a theoretical approach leading to a deep reflection about the real situation of the Brazilian Sign Language in the development of school education of the deaf individual, based on four intercomplementary points of view from the fields of Philosophy, Linguistics and Social Psychology. With this analysis, as a conclusion, the focus is on the issue of school education of the deaf and the role that the development of a full linguistic statute for the Brazilian Sign Language can play in the education of the deaf.
\end{abstract}

KEYWORDS: Brazilian Sign Language - LIBRAS. Stigma. Education of the deaf.

\section{INTRODUÇÁO}

Este estudo tem por objetivo analisar o estatuto linguístico da Língua Brasileira de Sinais (LIBRAS) e as restrições que lhe têm sido impostas em virtude da sobreposição de valores oriundos de representaçóes sociais e acadêmicas referentes à palavra. Empregada aqui como alegoria das línguas faladas, a palavra assume um papel central na composição da identidade do Homem, desde o sagrado vínculo com Deus, no campo das religióes, até a razão moderna, no campo da cultura acadêmico-científica. Defende-se, aqui, que apenas parcialmente se obteve êxito na determinação do estatuto linguístico da LIBRAS, pois, em que pese seu reco-

\footnotetext{
${ }^{1}$ http://dx.doi.org/10.1590/s1413-65382519000300009

${ }^{2}$ Estudo realizado a partir de pesquisas financiadas pelo Programa Cientistas do Nosso Estado, da Fundação Carlos Chagas Filho de Amparo à Pesquisa do Estado do Rio de Janeiro (FAPERJ), pela Fundaçáo Centro de Ciências do Estado do Rio de Janeiro (CECIERJ) e pelo Programa PROCIENCIA da Universidade do Estado do Rio de Janeiro.

3 Doutor em Linguística Aplicada pela Pontifícia Universidade Católica (PUC-Rio). Professor Titular de Linguística Aplicada do Programa de Pós-Graduação em Educação da Universidade do Estado do Rio de Janeiro. senna@senna.pro.br. Rio de Janeiro/ Rio de Janeiro/Brasil. ORCID: https://orcid.org/0000-0002-1086-8829
} 
nhecimento como língua natural, ainda persiste uma leitura de sua estrutura e funcionamento baseada em pressupostos pertencentes ao domínio da palavra. Em consequência disso, tende-se a reforçar o estigma social do sujeito surdo, particularmente no contexto da educaçáo escolar, por meio do que se caracterizará como espetáculo da superação.

Com finalidade estritamente didática, os argumentos em que se sustenta este estudo apresentam-se divididos em quatro momentos. No primeiro deles, logo a seguir, caracteriza-se o papel da palavra na construção identitária do Homem como espécie, focalizando-a no corpo do discurso sagrado da religião judaico-cristá. A opção por essa religião deu-se pelo fato de tratar-se daquela que exerce maior influência, tanto no desenvolvimento da cultura acadêmico-científica que predomina ainda hoje ao redor do planeta, quanto pela consequente influência sobre a conformaçáo da instituição escolar e seus valores formativos.

A análise da "palavra" ou "verbo" no campo do sagrado oferece explicação para uma forte tendência a se tratar da língua como um fenômeno independente do sujeito e de sua intencionalidade. Tal tendência repercute na cultura acadêmica, o que se analisa no segundo momento do texto, chamado Da palavra ao gesto e os sistemas de expressäo, no qual se apresenta a origem de um nível representacional da palavra, aqui chamado língua, sobre o qual operam certos modos de organização. A partir desse nível de representação, compreendem-se as noçóes Saussureanas de faculdade de linguagem e sistemas de expressão. Em que pese a contribuição de Saussure para o reconhecimento de sistemas de expressão gestuais como legítimos e naturais, ainda pesa sobre os sistemas não verbais a ausência de uma organização assemelhável à natureza da razão humana. Esta é a questão abordada no momento posterior do estudo, denominado $O$ corpo, a estrutura e os sistemas de expressão, no qual se analisa a natureza das hipóteses formuladas no campo da linguística para explicar a vinculação orgânica dos sistemas de expressão verbal com o corpo. No centro dessas hipóteses, encontra-se a noção de estrutura, com a qual se busca descrever as unidades e os modos de organizaçáo da fala. Tendo por pressupostos valores e princípios fortemente inspirados em hipóteses acerca da organizaçâo interna dos sistemas verbais, assim como de sua relação com certa presumida forma de pensar, noçóes como a de estrutura concorrem objetivamente para que qualquer sistema de expressão que não se sujeite à descrição por meio dela passe a ocupar um lugar de desprestígio.

Defende-se, entâo, que toda essa cultura relacionada à palavra se impóe sobre a LIBRAS, negando-lhe um pleno estatuto linguístico e contribuindo para o reforço ao estigma da surdez. No quarto e último momento do texto, analisa-se a condição do estigma da surdez a partir do ponto de vista da privaçáo da palavra, assim como o problema da tentativa de absorção da cultura da palavra como tentativa de superação. Com essa análise, a título de conclusão, focaliza-se a questão da educação escolar do surdo e o papel que nela pode exercer o desenvolvimento de um estatuto linguístico pleno para a LIBRAS.

\section{A palavra, o sagrado E O HOMEM}

Do ponto de vista estritamente fisiológico, a fala nada mais é do que uma vocalização derivada da projeção de ar sobre as pregas vocais por meio das vias aéreas. Dentre os sons vocalizados que se produzem dessa mesma forma, alguns destacam-se pela intencionalidade, tornando-se, mais do que vocalizaçóes, enunciaçôes. No domínio da linguística, as enunciaçóes 
são definidas como produto de um enunciado, a este podendo-se compreender como o contexto de comunicação em que se empregam enunciaçôes. O enunciado, também chamado de discurso, é o que propriamente define a intencionalidade ${ }^{4}$ das palavras enunciadas. Nos termos de Dubois et al. (1994, p. 181), a enunciação caracteriza-se a partir de três propriedades: (i) a possibilidade de o sujeito falante modalizar o enunciado, seja assumindo para si a veracidade do que é expresso (por exemplo, "afirmo aqui que o réu cometeu o delito e sua condenação é necessária”), seja modalizando-a de forma subjuntiva (por exemplo, "talvez seja possível que o réu tenha cometido algum delito e sua condenação possa tornar-se necessária”); (ii) o nível de transparência ou opacidade com que se dá a conhecer a informação por meio do enunciado; (iii) o nível de tensão que se dá na relação entre o falante e o interlocutor, a qual, não só interfere no processo em si da enunciação, mas também regula o tipo de enunciado a ser empregado a partir de diferentes tipos de registros e regras de formalidade; (iv) a simulação, no âmbito da qual se consideram os recursos diversos com que o falante manipula a relação do interlocutor com a informação, envolvendo metáforas, ironias, omissóes de pontos de vista etc. Ainda que se possam arrolar tantas outras propriedades da enunciação, as quatro apresentadas nos permitem ilustrar a natureza das decisóes tomadas pelo falante e, a partir delas, definir o que se compreende propriamente como intencionalidade no campo da linguística: uma série de decisóes que asseguram à fala o estatuto de código linguístico.

A associação da fala à intencionalidade é relativamente recente no campo das ciências da linguagem e ainda não é universal. Não raro, o estudo do código linguístico já houve por desprezar a intencionalidade, bastando-se à descrição atômica de sua forma estrutural, sob a justificativa de que, dessa forma, obter-se-ia maior potencial científico. É o que é apresentado em Bloomfield (1926, p. 45-47):

The method of postulates (that is, assumptions or axioms) and definitions is fully adequate to mathematics; as for other sciences, the more complex their subject-matter, the less amenable are they to this method, since, under it, every descriptive or historical fact becomes the subject of a new postulate. Nevertheless, the postulational method can further the study of language, because it forces us to state explicitly whatever we assume, to define our terms, and to decide what things may exist independently and what things are interdependent.

$[\ldots]$.

Also, the postulational method saves discussion, because it limits our statements to a defined terminology; in particular, it cuts us off from psychological dispute. Discussion of the fundamentals of our science seems to consist one half of obvious truisms, and one half of metaphysics; this is characteristic of matters which form no real part of a subject: they should properly be disposed of by merely naming certain concepts as belonging to the domain of other sciences. [...].

1. Definition. An act of speech is an utterance.

2. Assumption 1. Within certain communities successive utterances are alike or partly alike. [...].

3. Def. Any such community is a speech-community.

4. Def. The totality of utterances that can be made in a speech- community is the language of that speech-community.

$[\ldots]$.

${ }^{4}$ Nấo se confundir com intencionalidade nos termos da fenomenologia de E. Husserl (p. ex.: Husserl, 1994), na qual está relacionada à consciência que o sujeito detém de suas representaçóes de mundo a partir daquilo do mundo que se lhe apresenta, rompendo, assim, com o racionalismo de motivação inatista que lhe precedeu na filosofia dos iluministas e com as correntes do positivismo acadêmico que lhe foram contemporâneas. 
6. Def. The vocal features common to same or partly same utterances are forms; the corresponding stimulus-reaction features are meanings. Thus a form is a recurrent vocal feature which has meaning, and a meaning is a recurrent stimulus-reaction feature which corresponds to a form. 7. Assumption 2. Every utterance is made up wholly of forms. ${ }^{5}$

Observa-se, no excerto de Bloomfield (1926), o esvaziamento da figura do falante, ao mesmo tempo que se esvazia o componente social da língua, em favor de uma abordagem que a toma como uma entidade autônoma, com vida e funcionamento regulados por leis de certa lógica estrutural que lhe é inerente. Até mesmo o significado das estruturas deriva de reaçóes comportamentais, de modo que, neste tipo de estudo linguístico, o sujeito falante não detém qualquer tipo de controle sobre a língua e, consequentemente, sobre o processo de enunciação, o qual se explica a partir do condicionamento em feixes de estímulos e de respostas.

Ainda que estudos com esse perfil teórico tenham um viés muito específico, inúmeros outros, mesmo entre os mais recentes, apresentam algum traço em comum, sempre associados à ideia de que a língua possa ser arrolada como uma entidade autônoma, cuja estrutura e funcionamento existam sem relação com outros domínios simbólicos do Homem. Mesmo em correntes teóricas fortemente associadas à fisiologia, como é o caso do gerativismo pós-transformacionalista, hoje fortemente ligado a pesquisas no campo das neurociências, a língua não se analisa em suas relaçóes com os demais domínios da mente, mas, sim, em suas possíveis relaçóes com dispositivos neurofisiológicos especializados em operações linguísticas.

A motivação desses estudos - esta sim nos interessa aqui - advém de uma cultura que derivou um conceito social da língua, de certo modo dissociado da figura do Homem. Milhares de anos antes que os filósofos gregos introduzissem na cultura ocidental alguma reflexão sobre a natureza dos fatos da língua no universo das representaçóes humanas, esta já habitava o imaginário de todas as civilizaçóes conhecidas, não exatamente no lugar do Homem, mas no da transcendência, mais exatamente no entrelugar que se estabelece entre o Homem e o sagrado. Todas as formas de religião conhecidas partem da palavra e a ela atribuem propriedades transcendentais.

Na bíblia católica, por exemplo, encontram-se 1.239 ocorrências do termo [palavra], o que corresponde a $22 \%$ do número de vezes em que se cita a Deus (5.421 ocorrências) e 37 a mais do que se cita a Jesus (1.202 ocorrências). Além disso, somando-se as ocorrências de

\footnotetext{
${ }^{5}$ Tradução: $\mathrm{O}$ método dos postulados (isto é, suposiçôes ou axiomas) e definiçôes é totalmente adequado à matemática; quanto a outras ciências, quanto mais complexo é o seu assunto, menos eles se adaptam a esse método, já que, sob ele, todo fato descritivo ou histórico torna-se objeto de um novo postulado. No entanto, o método postulacional pode promover o estudo da linguagem, porque nos obriga a declarar explicitamente tudo o que assumimos, a definir nossos termos e a decidir quais coisas podem existir independentemente e quais são interdependentes. [...]. Além disso, o método postulacional economiza discussão, porque limita nossas declaraçôes a uma terminologia definida; em particular, nos impede de disputas psicológicas. A discussão dos fundamentos de nossa ciência parece consistir em uma metade dos óbvios truísmos e em uma metade da metafísica; isso é característico de questôes que não fazem parte real de um assunto: elas devem ser apropriadamente descartadas simplesmente nomeando certos conceitos como pertencentes ao domínio de outras ciências. [...]. 1. Definição. Um ato de fala é um enunciado. 2. Suposição 1. Dentro de certas comunidades, declaraçóes sucessivas são iguais ou parciais. [...] 3. Def. Qualquer comunidade desse tipo é uma comunidade de fala. 4. Def. A totalidade dos enunciados que podem ser feitos em uma comunidade de fala é a linguagem dessa comunidade de fala. [...]. 6. Def. As características vocais comuns aos mesmos enunciados ou parcialmente iguais são formas; as características de estímulo-reação correspondentes são significados. Assim, uma forma é uma característica vocal recorrente que tem significado, e um significado é uma característica recorrente de estímulo-reação que corresponde a uma forma. 7. Suposição 2. Todo enunciado é composto inteiramente de formas.
} 
termos associados a atividades verbais, como [louvar], [adorar], [aclamar], [evocar], [dizer] e [falar], resulta o total de aproximadamente 5.300. Ao todo, a bíblia apresenta cerca de 6.539 ocorrências de termos associados apenas à palavra e seus usos. Embora não se tenham pesquisado outros contextos, é presumível que o mesmo se dê em todos os termos sagrados.

Não obstante as variaçóes significativas entre as religióes, a palavra é um dado comum a todas. A palavra evoca a Deus, cura, prediz, explica, conforta, enfim, é propriamente o início, o meio e o fim. Na bíblia, nos termos do Antigo e do Novo Testamento, a palavra tem caráter atômico e essencial, nos seguintes termos:

\section{Eclesiástico (A.T.)}

3. A sabedoria foi criada antes de todas as coisas, a inteligência prudente existe antes dos séculos!

4. O verbo de Deus nos céus é fonte de sabedoria, seus caminhos são os mandamentos eternos.

5. A quem foi revelada a raiz da sabedoria? Quem pode discernir os seus artifícios?

6. A quem foi mostrada e revelada a ciência da sabedoria? Quem pode compreender a multiplicidade de seus caminhos?

7. Somente o Altíssimo, criador onipotente, rei poderoso e infinitamente temível, Deus dominador, sentado no seu trono;

8. foi ele quem a criou no Espírito Santo, quem a viu, numerada e medida;

9. ele a espargiu em todas as suas obras, sobre toda a carne, à medida que a repartiu, e deu-a àqueles que a amavam. ${ }^{6}$

\section{Evangelho segundo João (N.T.)}

No princípio era o Verbo, e o Verbo estava junto de Deus e o Verbo era Deus.

Ele estava no princípio junto de Deus.

Tudo foi feito por ele, e sem ele nada foi feito.

Nele havia a vida, e a vida era a luz dos homens.

A luz resplandece nas trevas, e as trevas não a compreenderam.

Houve um homem, enviado por Deus, que se chamava Joâo.

Este veio como testemunha, para dar testemunho da luz, a fim de que todos cressem por meio dele.

Não era ele a luz, mas veio para dar testemunho da luz.

[O Verbo] era a verdadeira luz que, vindo ao mundo, ilumina todo homem.

Estava no mundo e o mundo foi feito por ele, e o mundo não o reconheceu.

Veio para o que era seu, mas os seus não o receberam.

Mas a todos aqueles que o receberam, aos que creem no seu nome, deu-lhes o poder de se tornarem filhos de Deus,

os quais náo nasceram do sangue, nem da vontade da carne, nem da vontade do homem, mas sim de Deus.

E o Verbo se fez carne e habitou entre nós, e vimos sua glória, a glória que o Filho único recebe do seu Pai, cheio de graça e de verdade (grifos nossos).

Dos trechos anteriores, destaquem-se os seguintes aspectos atribuídos à palavra: em primeiro lugar, o poder que emana de sua natureza a confundir-se com a de Deus (“...e o verbo era Deus...”); nessa perspectiva, o verbo é acima de tudo o poder e a força de Deus criador; em seguida, em ambos os textos, o verbo é anterior ao tempo, anterior a tudo exceto Deus, de sorte que não se institui, mas é instituinte de tudo e de todos, incluindo-se, naturalmente, o Homem; contudo, "E o verbo se fez carne e habitou em nós...", disso resultando um terceiro aspecto a se considerar, qual seja o de que a palavra, mesmo nos habitando, é uma força que vem de fora, que tem uma existência que nos transcende. Essa é verdadeira origem de uma concepção de

${ }^{6}$ Recuperado em 20 junho de 2019 de https://www.bibliacatolica.com.br/biblia-ave-maria/eclesiastico/.

${ }^{7}$ Recuperado em 20 junho de 2019 de https://www.bibliacatolica.com.br/biblia-ave-maria/sao-joao/. 
língua que a toma como uma entidade cuja vida e o funcionamento situem-se para além do Homem em que meramente habita.

Somente a partir dessa concepção, pode-se compreender o que de fato motiva a linguística a tratar da língua como um fato em si mesmo, isolado do sujeito falante que a utiliza. Ademais, explica como se sustentar a hipótese de que um som - uma mera vocalização - possa tornar-se um traço estrutural de certa língua, nos termos como Bloomfield (1926) apresenta. Fato é que, todavia, vocalizaçóes de fala analisadas fora do contexto da intencionalidade não se distinguem de outras formas de vocalização, de certo modo, táo complexas quanto as da fala, conforme aponta Oliveira Filho (1968) no excerto que se apresenta a seguir:

Certo, entáo, de que linguagem passou de fato biológico a fato social já entre os primatas inferiores e de que a linguagem do macaco japonês (macaca fuscata) não teria a grande importância que lhe estão atribuindo se não fosse realmente um instrumento de comunicação de certa eficiência, J. Itani dá uma atenção especial a essa função da linguagem entre os macacos de seu país, donde o empenho em procura, a cada passo, a relação real entre os diferentes tipos de vocalizaçóes e os comportamentos diversos quer na comunicaçóes entre um macaco e o resto do bando, quer, especialmente, nas comunicaçôes entre um e outro ("diálogo"). (Oliveira Filho, 1968, p. 229).

O estatuto de língua que a priori os linguistas imprimem às vocalizações humanas empregadas sob condiçôes sociais específicas, sustenta-se tão somente na crença, anterior, em uma entidade de caráter autônomo e com forte status de poder assegurado por sua presumida proveniência divina.

Ainda nessa mesma perspectiva, encontra-se um outro aspecto relevante para este trabalho, que se refere à relação do verbo com a sabedoria de Deus, ou melhor, ao verbo como a própria sabedoria de Deus. Tal relação de que trata o livro do Eclesiástico é retomada na Bíblia ainda nos livros dos Números e da Sabedoria, todos pertencentes ao Antigo Testamento. A sabedoria, que é o verbo de Deus, "ele a espargiu em todas as suas obras, sobre toda a carne", legando-a, desse modo, ao Homem, propriamente "àqueles que a amavam”. A sabedoria é, pois, louvar a Deus com o próprio verbo que é Deus, tornando-se um filho de Deus. O verbo torna-se a chave da relação do Homem com sua transcendência em Deus e, simultaneamente, torna-se a sua consciência. Por isso bem se explica a presença de tantas ocorrências do termo [palavra] e dos termos associados a atividades verbais no corpo da Bíblia.

\section{Da PALAVRa Ao geSto E OS SISTEMAS DE EXPRESSÃo}

Não obstante suas bases culturais no campo do sagrado, a palavra impregna-se, também, na cultura acadêmica, sobretudo devido à relação que, já desde a religião, se institui entre o verbo e a inteligência. Alguns marcos históricos da cultura científica nos proporcionam dados para compreender o lugar central da palavra no gradual processo de caracterização do homem fora do discurso religioso no ocidente. No ontológico texto do Discurso do Método (Descartes, s.d.), a razão e a palavra figuram como propriedades essencialmente responsáveis pela distinção entre o Homem e os demais animais.

O que não parecerá de maneira alguma estranho a quem, sabendo quão diversos autômatos, ou máquinas móveis, a indústria dos homens pode produzir, sem aplicar nisso senão pouquíssimas peças, em comparaçáo à grande quantidade de ossos, músculos, nervos, artérias, veias e todas as outras partes existentes no corpo de cada animal, considerará esse corpo uma máquina que, tendo sido feita pelas máos de Deus, é incomparavelmente mais bem organizada e capaz de movimentos mais admiráveis do que qualquer uma das que possam ser criadas pelos homens. 
(\$) E me demorara especificamente neste ponto, para mostrar que, se existissem máquinas assim, que fossem providas de órgáos e do aspecto de um macaco, ou de qualquer outro animal irracional, não teríamos meio algum para reconhecer que elas não seriam em tudo da mesma natureza que esses animais; contudo, se existissem outras que se assemelhassem com os nossos corpos e imitassem tanto nossas açōes quanto moralmente fosse possível, teríamos sempre dois meios bastante seguros para constatar que nem por isso seriam verdadeiros homens. Desses meios, o primeiro é que jamais poderiam utilizar palavras, nem outros sinais, arranjando-os, como fazemos para manifestar aos outros os nossos pensamentos. (Descartes, s.d., p. 116-117).

Descartes avança significativamente na introdução de alguma intencionalidade como propriedade da palavra, já arrolada como instrumento de manifestaçấo do pensamento. Com isso, observe-se, já é possível tratar da palavra e da razão como coisas distintas. Mais do que isso, a palavra não tem, per si, a propriedade de expressar o pensamento, pois depende de certos "arranjos" aplicados pelos Homens. São esses ditos arranjos que podemos aqui associar aos traços constituintes da intencionalidade, o que propriamente caracteriza um ser humano atuando sobre a razão. Segundo Descartes, portanto, palavras não se tornam línguas por serem palavras, mas, sim, por serem empregadas segundo certos arranjos que nos proporcionam a capacidade de expressar o pensamento. Em consequência disso, Descartes abre-se, de forma revolucionária em seu momento histórico, para que outros recursos da chamada máquina humana sejam igualmente reconhecidos como línguas, tal como ele mesmo nos anuncia:

Note-se que, por esses dois meios, pode-se também conhecer a diferença que há entre os homens e os animais. Já que é algo extraordinário que não existam homens tão embrutecidos e tấo estúpidos, sem nem mesmo a exceção dos loucos, que não tenham a capacidade de ordenar diversas palavras, arranjando-as num discurso mediante o qual consigam fazer entender seus pensamentos; e que, ao contrário, não haja outro animal, por mais perfeito que possa ser, capaz de fazer o mesmo. E isso não ocorre porque lhes faltem órgãos, pois sabemos que as pegas e os papagaios podem articular palavras assim como nós, no entanto não conseguem falar como nós, ou seja, demonstrando que pensam o que dizem; enquanto os homens que, havendo nascido surdos e mudos, são desprovidos dos órgãos que servem aos outros para falar, tanto ou mais que os animais, costumam criar eles mesmos alguns sinais, mediante os quais se fazem entender por quem, convivendo com eles, disponha de tempo para aprender a sua lingua. E isso não prova somente que os animais possuem menos razão do que os homens, mas que não possuem nenhuma razão. (Descartes, s.d., p. 118, grifos nossos).

A presença de uma língua de sinais entre os surdos surpreende no discurso de Descartes, haja vista a máxima cogito ergo sum ("penso, logo existo") que, entre os filósofos iluministas, marca uma ruptura entre o pensamento moderno e a materialidade do corpo. Essa presença de uma língua corpórea sustenta-se, todavia, no fato de que a natureza do objeto considerado por Descartes não é o ato ou matéria da expressão, mas, sim, a língua, o arranjo intencional que liga o pensamento ao dado expresso. É, portanto, um fenômeno mental o que se estaria tomando por língua.

É nesse nível de representação de uma língua que opera a tradução do pensamento em que se encontra a melhor explicação para o conceito de categoria presente na filosofia de Kant, notadamente no Crítica da Razão Pura (publicada pela primeira vez em 1781), publicado cerca de um século após $O$ discurso do método. Embora não se confunda com o pensamento, 
a língua, como nível de representação dos conceitos, é o repositório das categorias a priori do pensamento, a saber:

Podem fazer-se sobre esta tábua das categorias consideraçóes mui curiosas, suscetíveis de proporcionar-nos talvez consequências mui importantes para a forma científica de todos os conhecimentos racionais. Com efeito, é fácil compreender que esta tábua serve extraordinariamente para a parte teórica da Filosofia e é indispensável para o plano completo de uma ciência, enquanto tal ciência se baseie em princípios "a priori" e para dividi-la matematicamente segundo princípios determinados. $(\$)$ Basta para convencer-se disto pensar que esta tábua contém completamente todos os conceitos elementares do entendimento e também a forma do sistema dos mesmos na inteligência humana, e que, por conseguinte, nos indica todos os momentos de uma ciência especulativa projetada assim como também sua ordenação. (Kant, 2016, p. 80).

Compreende-se com Kant e Descartes que o pensamento se desenvolve a partir de instrumentos peculiares da razão, suas categorias, associados a arranjos conceituais que se desenvolvem no nível da língua, não da palavra ou dos sinais. A relação das propriedades do pensamento com a experiência de mundo, segundo Kant, imprescindível, não altera o fato de que existam um pensamento e uma língua a priori, os quais regem tanto os sistemas de expressão, quanto os arranjos possíveis de seu funcionamento. Assim sendo, em que pesem as mais significativas diferenças entre os vários tipos de sistemas de expressão, sejam formados por palavras ou sinais, sua natureza a priori é sempre a mesma. A questáo que resta a questionar aqui é o fato de que, assim considerada a língua, todas as suas propriedades residiriam exclusivamente no âmbito da mente, mais especificamente, no do pensamento, daí resultando impossível se analisar o impacto das diferenças entre os sistemas de expressáo no perfil dos sujeitos que os empregam.

No advento dos primeiros estudos específicos da entáo recente ciência da linguística, publicavam-se em obra póstuma os trabalhos de Ferdinand Saussure, que chegaram em um só livro denominado Cours de linguistique générale (1916). A obra de Saussure traz uma contribuição importante para o tratamento do problema levantado no parágrafo anterior, por meio da apresentação de uma chamada faculdade de linguagem. Por meio dela, define-se um traço da espécie humana que lhe faculta desenvolver e operar sistemas de expressão das mais variadas ordens, desde as verbais, como as línguas naturais e as línguas escritas alfabéticas, às não verbais, igualmente divididas entre naturais, como a LIBRAS, e as artificiais. Em Saussure (1916), tanto a faculdade de linguagem como os sistemas de expressão derivados são apreciados exclusivamente do ponto de vista de sua conformação propriamente linguística, seja quanto à forma estrutural, seja quanto às dinâmicas de sua organizaçáo funcional. No plano da representação do pensamento, a teoria de Saussure reporta-se apenas àquilo que, segundo ele, interfere na estrutura dos sistemas e na seleção de palavras que compõem as unidades de sentido. Tratase, nesse caso, das relaçôes associativas, com base nas quais se definem as ideias que se podem articular dentro dos chamados sintagmas (unidades básicas de sentido dentro de uma dada estrutura). Por exemplo, no universo de mundo compartilhado pela maioria das pessoas, uma relação associativa entre ${ }_{n}$ [residência] $e_{v}\left[\right.$ morar] é válida, ao passo que outra entre ${ }_{n}$ [violáo] e „ [almoçar] seria inválida.

A contribuição de Saussure soma-se à de Descartes, na medida em que assegura a todos os sistemas de expressão, sem primazias, o mesmo status, todos igualmente vinculados à filogenia do ser humano. Uma faculdade de linguagem atribui aos sistemas de expressão 
uma materialidade biológica, resolvendo, assim, a questão da sua origem, antes vinculada ao sagrado. Mais avante, porém, Saussure reconhece que os sistemas derivados não se bastam em si, porém se sustentam nas práticas sociais, devendo assim, ser objeto de uma ciência maior do que a linguística, a semiótica.

À semiótica compete o estudo dos processos de significação, das intencionalidades, portanto, que imprimem sentidos aos signos de um sistema de expressão. Ao arrolar tal área mais ampla, Saussure reconhece que todo sistema de expressão sintetiza, ao mesmo tempo, um componente derivado dos processos do pensamento (no âmbito das categorias abordadas em Kant (2016) e um outro, derivado da experiência psicossocial, subjetiva e histórica. É desse modo que se pode determinar que nenhum sistema de expressão, ainda que derivado de uma faculdade universal, se constitua à margem de uma cultura que nele se impregne, tornando-se parte de sua forma e organização.

Apesar disso, entretanto, a proposição de uma faculdade de linguagem ainda não é bastante para vincular em definitivo os sistemas de expressão ao corpo, como se analisa na próxima seção.

\section{O CORPO, A ESTRUTURA E OS SISTEMAS DE EXPRESSÃO}

Sistemas de expressão gestuais, como a LIBRAS, beneficiam-se da noção de uma faculdade de linguagem que lhe confere o mesmo estatuto de língua, no sentido aqui apresentado, associado às línguas faladas. Só isso, no entanto, não lhe satisfaz plenamente, pois o estatuto de língua confere um status genérico cuja validade depende da natureza dos chamados arranjos que possibilitam a expressão do pensamento. Nessa questão, reside propriamente o problema da integração de sujeitos surdos usuários proficientes de LIBRAS em contextos fortemente marcados por modelos intelectuais acadêmico-científicos, como a escola. Tal problema pode ser definido, tanto pela diferença entre o status já consagrado da LIBRAS como uma língua plenamente constituída como sistema de expressão natural e efetivamente empregada de forma intencional, quanto por seu status como sistema de expressão racional, capaz de facultar ao usuário proficiente o mesmo potencial que o falante, para pensar, ou seja, identificar o operar categorias lógico-formais, conceituar, fixar cadeias causais no tempo etc.

A relação entre o pensamento e as unidades dos sistemas verbais, assim como suas formas de organização, é consagrada, tanto nos extratos sagrados, quanto na cultura acadêmico-científica. Sugere-se haver entre si uma relação ontológica que, como já vimos aqui, costuma-se associar ao poder de Deus. Dá-se, entretanto, que tal relação com o pensamento não se consagrou associar a outros sistemas de expressão que não à fala, exceto àqueles derivados da própria cultura científica, de caráter específico, como a escrita, a matemática, as linguagens artificiais da computação etc. A LIBRAS, assim como outros sistemas de expressão análogos, prejudicam-se sobremaneira no âmbito de uma tal relação com o pensamento, pois suas estruturas e formas de organização não se submetem à ordem das estruturas que se consagraram na cultura acadêmica.

Costuma-se associar o surgimento da ciência linguística à apresentação das primeiras aplicações da noção de estrutura no processo de descrição frasal. A estrutura é, na realidade, uma alegoria advinda do campo das ciências médicas, no qual se desenvolveu o conceito de 
sistema como um feixe de estruturas que operam solidariamente para cumprir certa função orgânica. Daí se definiram os sistemas respiratório, circulatório, digestório etc. Transferido para a o campo das ciências da linguagem - notadamente o da linguística - a noçáo de sistema foi aplicada à caracterização das línguas como uma destas funçôes orgânicas do Homem, promovida e regida pela faculdade de linguagem. Fato é que, entretanto, na medicina, as estruturas e os modos de sua organização nos sistemas fisiológicos são estudados e descritos a partir de evidências clínicas, ao passo que, na linguística, os diferentes sistemas - ou seja, as diferentes línguas - explicam-se a partir de hipóteses que partem de categorias e unidades absolutamente desprovidas de matéria, de natureza simbólica e histórica. Assim, por exemplo, as diferenças de significado no verbo ${ }_{\mathrm{v}}$ [arrasar] empregado nas frases 1 a $3 \ldots$

1. A cantora arrasou.

2. A cantora arrasou a bailarina que errou o passo.

3. A cantora arrasou o show.

... não se explicam a partir de alguma noção sistêmica ou arranjo de palavras, mas, sim, a partir de pura idiossincrasia cultural. Em português, [arrasar] pode ser empregado com os sentidos de "resultar bem-sucedido", "repreender contundentemente", ou "levar ao fracasso". Além disso, a descriçâo linguística das línguas naturais herda diversos pressupostos acerca das suas unidades categoriais, influenciados por certa forma particular de "querer ver" as partes da frase. Assim, por exemplo, optou-se por considerar os artigos e outros determinantes como entes gramaticais isolados dos substantivos que determinam na sentença, com os quais sempre formam estruturas (por exemplo: $\{[a] \longrightarrow[$ cantora $]\}$ ). Contudo, por que postular essa dissociação e não um vínculo, como, por exemplo, em certa palavra única [acantora]? Se a justificativa para não o fazer é o fato de que o artigo pode facilmente ser comutado com algum outro determinante (\{[essa][cantora $]\})$, então, por que não postular dois termos separados dentro do próprio substantivo $(\{[$ cantor $][a]\})$, já que a desinência de gênero pode ser comutada com outros morfemas ( p. ex., [-es] )? A justificativa é tampouco semântica, pois artigos definidos são termos gramaticais sem valor semântico, ao passo que as desinências de gênero e número tem um significado bastante transparente.

Fronteiras entre palavras de uma frase, ou mesmo fronteiras entre unidades funcionais de frases, como sujeitos ou complementos verbais, não são fatos da língua propriamente, mas da interpretação que dela se faça. Isso explica por que crianças em processo de alfabetização apresentam escritas com palavras truncadas ou justapostas em alguma fase do aprendizado: "menoto" por "minha moto", "aranja" por "a laranja".

Toda a idiossincrasia no processo de descrição gramatical é, entretanto, desprezada no discurso da linguística e na cultura letrada, de modo que se tornou normal crer que a língua seja, de fato, o que se apresenta como mera hipótese descritiva. E por força das tradiçóes culturais - seja no âmbito do sagrado, seja no do acadêmico-científico - assumiu-se que essa suposta normalidade decorre da relação direta entre o pensamento e a língua. Esse conjunto de pressuposiçóes e sua normalidade presumida conferiu legitimidade à noção de estrutura na cultura linguística, conferindo-lhe um estatuto biológico. A estrutura, portanto, é considerada parte da fisiologia humana. 
Nessa perspectiva, qualquer língua que se sustente em sistemas de expressão que não se sujeitem a descrições baseadas na concepção de estrutura fica sujeita a um status distinto do das línguas verbais. Distinto e, do ponto de vista da cultura escolar, inferior, pois que se trataria de uma língua alienada da estrutura do pensamento. É o caso da LIBRAS, cujo status de língua contrasta com seu status na cultura escolar.

Convém recordar que, como já nos dissera Saussure, toda língua se institui em uma cultura, que a legitima como forma e modo de organização. O caso da LIBRAS reporta-nos, portanto, a uma situação de clara discriminação cultural, que lhe afeta, mais do que no âmbito de sua definição como língua, no de seu estatuto como sistema de expressão vinculado à experiência psicossocial, subjetiva e histórica da cultura surda.

\section{A palaVra e O eSTigma Na EDUCAÇÃo de SURDos}

A situação da LIBRAS no contexto de coisas de que se vem tratando neste estudo reporta à questão do processo de inclusão escolar dos surdos, que tem, por um lado, amparo em um consistente regimento legal, porém, por outro lado, ainda caminha com muita dificuldade no que concerne integração do aluno surdo no ensino-aprendizagem. A natureza dos processos contemporâneos de inclusão social, dentre eles a inclusão escolar, merece uma reflexão, pois:

A atmosfera de inclusão que se instalou nessas últimas décadas e que exige a todo o momento um tratamento igualitário aos supostamente "diferentes" de diversas ordens seria um refinamento da produção dos diferentes. Novas palavras, novas práticas? Ou antigas práticas (re)atualizadas? Incluir para observar, encaixar, colocar num ponto estratégico de observaçáo dos desvios? Estaríamos, na escola inclusiva, preparados para lidar com ambiguidades, ambivalências, indefinições, "diferenças", sem, contudo, estigmatizar, delimitar espaços, estabelecer fronteiras fixadas de forma concreta ou imaginária?. (Schilling \& Miyashiro, 2008, p. 247).

De uma forma ou de outra, o estigma não se supera com a inclusão. Nos termos de Goffman (1981), estigma é o traço indesejável que distingue aquele que não é autorizado a incluir-se. Não se trata de um "outro" indivíduo qualquer, pois que o meu outro é um possível; trata-se do "não individuo", o que não há de se tornar um outro de mim. Antes de tudo, portanto, o estigma é o veto a que alguém se torne "outro" na sociedade; é o impedimento e a justificativa para o banimento social. No Brasil, a educaçáo pública é povoada por estigmas os mais diversos, sempre relacionados a estados de fracasso de aprendizagem, supostos distúrbios de comportamento, surtos de indisciplina e insubordinação, de modo que a condição do indivíduo escolar constitui-se um eterno "tornar-se aluno", nos termos de Castro (2015), a partir de um estudo etnográfico. Segundo a autora:

Os conceitos de pertencimento e resiliência em relação aos processos de escolarização servem como cenário para a compreensão sobre o tornar-se aluno. Entende-se que é através do pertencimento que os alunos podem legitimar suas identidades em seus diferentes contextos de convivência, sobretudo, na escola. Pertencer significa partilhar características, vivências e experiências com outros membros das comunidades de pertencimento, desenvolvendo sentimento de pertença. (\$) [...]. Do mesmo modo, pode-se observar como ocorre o pertencimento nas comunidades escolares, nas quais, os alunos vão idiossincraticamente identificando as práticas de sala de aula que os conduzirão à condição, por exemplo, de bons e maus alunos pelo desempenho escolar. Ocorre que esse desempenho é atribuído não somente pelas vivências do aluno em sala de aula e na realização das atividades pedagógicas, mas também por uma série 
de características, muitas vezes subjetivas. Isso porque é o próprio aluno que acentua e revela o que é importante para pertencer à escola e à sala de aula. A partir desse conceito de pertencimento e suas características aplicadas ao aluno e à escola como um todo, pode ser facilitado o entendimento do processo de pertencimento, do que significa tornar-se aluno e de como se dá a pertença dos mesmos nesses contextos. (Castro, 2015, p. 39-42).

O estigma é um dos fatores que atuam impeditivamente no desenvolvimento do processo de pertencimento, o que, no cotidiano escolar, manifesta-se por meio de "uma série de características, muitas vezes subjetivas" (Castro, 2015, p. 42). Na maioria dos estudos na educação especial, o estigma é dado como traço material, centrado na figura da deficiência, que é dada ao sujeito como algo que "se porta", "se ostenta", o que bem se identifica na questionável expressão "portador de deficiência" (já dizia um amigo cadeirante: "não levo a paralisia na cadeira de rodas; a cadeira leva a mim”). Esse foco na deficiência seja, talvez, o que justifique na educação uma tendência a buscar absorvê-la nas práticas ordinárias do cotidiano escolar, visando à sua superação, à compensação; enfim, toda sorte de coisas que justifique o pertencimento do sujeito apesar do estigma.

Uma visão interessante deste tipo de situação encontra-se descrita em Moura (2015), no texto chamado "Corrigindo o estigma através do espetáculo: o caso da equipe de futebol de anóes". Trata-se de um time de futebol formado por jogadores anóes; poderiam ser cegos, paraplégicos, não importa; o que se destaca no trabalho é a tese de que o esporte faculta a superação do estigma ou, melhor dizendo, sua "correçâo". O espetáculo, assim dito, corrige: é preciso tornar-se sujeito do espetáculo que o senso comum reconhece como um espetáculo. Naquele jogo, o espetáculo não é o jogo em si, mas a superação.

No caso do surdo, o estigma reside, menos na privação do sentido, do que na privação da palavra, pois como visto anteriormente, a palavra perpassa a própria identidade humana, seja no domínio do sagrado, seja no da razão. Em seu caso, o espetáculo da superação está na oralização forçada, em uma palavra que se lhe impóe na esperança de permitir que tenha Deus dentro de si, ou alguma racionalidade que se perceba humana. Espetáculos não são, todavia, instrumentos que levem à superação do estigma, pois, tão logo se desfaça o cenário, resta o indivíduo, nu, e o estigma. A palavra é fortemente relacionada a estados de exclusão social, constituindo um traço com características de estigma não associado a deficiências de nenhuma ordem. O preconceito linguístico é objeto de preocupação em diferentes áreas do conhecimento e tratado como estigma em trabalhos como o de Araujo, Correa e Wolters (2016), na área de administração, para o qual:

Uma possível explicação para esse dado é o fato de, muitas vezes, as pessoas com sotaques de grupos dominantes serem percebidas como tendo status e 'poder, enquanto são percebidas com baixos níveis de sucesso socioeconômico as pessoas que possuem perfis de grupos menos dominantes [...]. De acordo com essa premissa, pode-se observar que nos quesitos como competência e inteligência, atributos desejados em cargos de elevado status social, os indivíduos possuidores de sotaques de grupos dominantes tendem a receber avaliaçóes mais positivas do os de grupos náo dominantes [...]. No entanto, no tocante aos quesitos bondade, cordialidade e solidariedade - características mais requisitadas em cargos de baixo status, indivíduos com sotaques que remetem a grupos náo dominantes tendem a ser avaliados de forma mais positiva. (Araujo, Correa, \& Wolters, 2016, p. 3). 
O preconceito e a estigmatização no campo da linguística não se restringem às línguas faladas, pois, embora os sotaques sejam estigmatizados, o preconceito repousa sobre outros fatores, como o poder, a identidade social do grupo de falantes etc. A presença da LIBRAS na educação brasileira tem caráter revolucionário, por possibilitar ao surdo tornar-se aluno a partir de sua própria língua materna, fato que concorre de forma bastante positiva para o desenvolvimento de sua identidade, seja escolar, seja social. Entretanto, o ingresso da LIBRAS na escola e na cultura acadêmica dá-se na forma do espetáculo, por meio da tentativa de absorvê-la pelo senso comum e a empregando como parte de expedientes para superação da deficiência. Em lugar de ter na centralidade do processo de escolarização o desenvolvimento do aluno surdo, a escola concede o direito à LIBRAS para torná-lo um aluno, "corrigindo-lhe" a deficiência.

Nisso consiste o que se dissera aqui anteriormente, quanto a se reconhecer na LIBRAS uma língua, porém desprezar seus modos de organização, em favor das teorias e dos modelos descritivos já consagrados na descrição do modo de organização da língua falada. Ocorre, porém, que surdos usuários correntes de LIBRAS organizam enunciados e consequentemente, sua representação de mundo, de forma singular com relação aos usuários das línguas faladas. Essa forma de organização peculiar à LIBRAS está diretamente relacionada à cultura surda, à identidade primária do sujeito surdo. Ao negá-la, em favor de uma inexistente analogia com a estrutura e o funcionamento da fala, nega-se à LIBRAS um pleno estatuto linguístico, autônomo e legítimo. Paralelamente, nega-se ao sujeito surdo o pleno estatuto como sujeito intelectual, como aluno, como pessoa.

A superação do estigma da palavra entre os surdos demanda necessariamente o estudo das propriedades organizacionais do sistema da LIBRAS, assim arrolada como língua detentora de um estatuto linguístico próprio. Não se trata de buscar fundamentos para práticas de superação de uma deficiência, já que não existe deficiência em alguma suposta ausência de palavras entre os surdos. Tampouco, trata-se de buscar encaixar a LIBRAS em teorias sobre supostas estruturas mentais que a liguem a algum modelo de pensamento culturalmente consagrado. Trata-se, isso sim, de buscar descrevê-la como um sistema organizacional singular, de todo coerente com a cultura surda e com a identidade, social e intelectual, daqueles que a detém como língua materna.

\section{Conclusāo}

A cultura escolar traz impregnada em si valores que se impóem sobre suas políticas e processos de inclusão, assim como no caso abordado neste ensaio, com impacto sobre a educação dos surdos. Dentre estes, os valores agregados à palavra e às línguas faladas concorrem muito fortemente no delineamento da figura do sujeito escolar, contribuindo para a conformação dos parâmetros de normalidade, tanto no plano da identidade perante a espécie humana, como no da intelectualidade. Como visto aqui, mesmo quanto à sua vinculação ao Homem, a palavra flutua entre o sagrado e uma representação mental, imaterial, a qual se explica por meio de conceitos como o de estrutura, não necessariamente excludentes entre si. Em que pese já ter sido conferida à LIBRAS o status de língua natural, esta e todos os demais sistemas de expressão não verbais têm sido descritos com base nos mesmos parâmetros derivados dos valores aplicados à palavra, com isto lhes furtando um pleno estatuto linguístico. 
Em consequência disso, o surdo, na educação inclusiva, segue sujeito ao que aqui se denominou espetáculo da superação. Em seu caso, em face de um estigma social que se revela na ausência da palavra falada, o espetáculo reside na tentativa de absorver a LIBRAS, assim como a cultura surda a ela subjacente, aos parâmetros organizacionais da fala. $\mathrm{O}$ vazio ainda por se preencher na definição do estatuto linguístico da LIBRAS pesa na inclusão social do surdo, sobretudo em sua escolarização. Por esse motivo, trata-se de objeto dos mais relevantes a ser incluído na agenda de estudos e pesquisas na área de educação de surdos.

\section{REFERÊNCIAS}

Araujo, B., Correa, F., \& Wolters, M. (2016). O sotaque estadunidense representa uma vantagem em decisóes de emprego no Brasil?. Revista de Administração Contemporânea, 20(6), 693-714. DOI: https://dx.doi.org/10.1590/1982-7849rac2016150181.

Bloomfield, L. (1926). A Set of Postulates for the Science of Language. Language, 2(3), 153-164.

Castro, P. A. (2015). Tornar-se aluno - identidade e pertencimento: perspectivas etnográficas. Campina Grande/PB: UEPB.

Descartes, R. (s.d.). O discurso do método. Traduçáo portuguesa J. C. Costa. Rio de Janeiro: Tecnoprint.

Dubois, J., Giacomo, M., Guespin, L, Marcellesi, C., Marcellesi, J.-B., \& Mével, J.-P. (1994). Dictionnaire de linguistique et des sciences du langage. Paris: Larousse.

Goffman, E. (1981). Estigma: notas sobre a manipulação da identidade deteriorada. Tradução portuguesa: M. B. Nunes. Rio de Janeiro: LTC.

Husserl, E. (1994). Méditations cartésiennes. Paris: P. Universitaire de France.

Kant, E. (2016). A crítica da razão pura. Tradução portuguesa M. Hulschof. Petrópolis: Vozes.

Moura, D. (2015). Corrigindo o estigma através do espetáculo: o caso da equipe de futebol de anóes. Revista Brasileira de Ciências do Esporte, 37(4), 341-347. DOI: https://dx.doi.org/10.1016/j. rbce.2015.08.002.

Oliveira Filho, A. (1968) Um ensaio de paleolinguística. Rio de Janeiro: Acadêmica.

Schiling, F., \& Miyashiro, S. (2008). Como incluir? O debate sobre o preconceito e o estigma na atualidade. Educação e Pesquisa, 34(2), 243-254. DOI: http://dx.doi.org/10.1590/S151797022008000200003

Submetido em 28/06/2019

Reformulado em 08/07/2019

Aceito em 09/07/2019 